\title{
Study of Control Strategies for Voltage-Source PWM Rectifier
}

\author{
Hui Wang ${ }^{1}$, Hui Qi ${ }^{1 *}$ \\ 1 Beijing University of Technology \\ Beijing, China \\ * Corresponding author: qihui@bjut.edu.cn
}

\begin{abstract}
The paper first analyzes the mathematical model of three-phase voltage-source PWM rectifier and then introduces double closed-loop control of voltage and current system, in which the active and reactive power can be controlled independently. PWM rectifier control system is built based on the DSP2812 after modeling and simulating in MATLAB / SIMULINK environment. The result shows that the system has the characteristic of good anti-interference performance and fast dynamic response.
\end{abstract}

Keywords-scene; PWM rectifier; feed-forward decoupling control; closed-loop control

\section{INTRODUCTION}

Diode rectified circuit and thyristor rectifiers circuit are widely used in the conventional rectifier circuit, but the problems arising during operating should not be ignored, such as, harmonic problems and low power factor. These problems may do harm to the grid, which in turn cause a series consequences, therefore, the application of such rectifier will be limited. With the continuous development of PWM technology nowadays, people pay attention to the PWM rectifier gradually. For convertor, PWM rectifier has many advantages which non-controlled rectifier does not have. For example, the power factor can be controlled, network side current has no harmonic and the power can flow in both directions. So the PWM rectifier is also called "green energy converter" $[1,2]$.

In this paper, the mathematical model of three-phase voltage rectifier in the three-phase stationary coordinates is analyzed firstly, which leads to the mathematical model in the two-phase stationary coordinates. After studying the direct current control technology and its feed-forward decoupling control technology in the two-phase stationary coordinates, it is simulated in MATLAB/SIMULINK environment and the PWM rectifier control system is built finally.

\section{THE MATHEMATICAL MODEL OF PWM RECTIFIER}

Topological of three-phase PWM rectifier is shown in Figure 1. Input inductor is mainly used as filter. AC-side current can be regarded as three-phase sinusoidal current. A large capacitor is used in DC-side to keep its voltage.

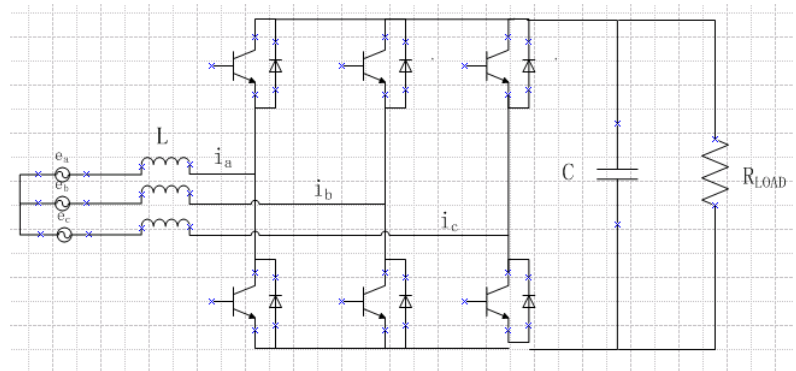

Figure 1. Topological of three-phase PWM rectifier

We establish the formula of voltage according to Kirchhoff's voltage law. Therefore, we can get the mathematical model of three-phase PWM rectifier in the three-phase stationary coordinates.

$$
\left\{\begin{array}{l}
L \frac{d i_{a}}{d t}+R i_{a}=u_{a}-e_{a} \\
L \frac{d i_{b}}{d t}+R i_{b}=u_{b}-e_{b} \\
L \frac{d i_{c}}{d t}+R i_{c}=u_{c}-e_{c}
\end{array}\right.
$$

Since three-phase power is in a balanced state, so

$$
\left\{\begin{array}{l}
e_{a}+e_{b}+e_{c}=0 \\
i_{a}+i_{b}+i_{c}=0
\end{array}\right.
$$

The physical meaning of the mathematical model of three-phase PWM rectifier in the three-phase equilibrium system is very intuitive and clear. However, AC system of three-phase is time-varying, so it is difficult to design system. So the mathematical model in the a-b-c three-phase stationary coordinates should be converted into the mathematical model in the d-q rotating coordinate, which is rotated according to the grid fundamental frequency.

The transformation matrix from three-phase stationary coordinate system to two-phase stationary coordinate system is shown as:

$$
C_{3 s / 2 s}=\left[\begin{array}{ccc}
1 & -\frac{1}{2} & -\frac{1}{2} \\
0 & \frac{\sqrt{3}}{2} & -\frac{\sqrt{3}}{2}
\end{array}\right]
$$

The transformation matrix from two-phase stationary coordinate system to two-phase synchronous rotating coordinate system is: 


$$
C_{2 s / 2 r}=\left[\begin{array}{cc}
\cos \theta & \sin \theta \\
-\sin \theta & \cos \theta
\end{array}\right]
$$

Using the theory of space vector and Clarke transformation, (2) is substituted into (1), and multiplied the result by (3), the mathematical model of three-phase stationary coordinate can be transformed into (5):

$$
\left\{\begin{array}{l}
L \frac{d i_{a}}{d t}+R i_{\alpha}=u_{\alpha}-e_{\alpha} ; \\
L \frac{d i_{\beta}}{d t}+R i_{\beta}=u_{\beta}-e_{\beta} ;
\end{array}\right.
$$

We can get the mathematical model of $d-q$ coordinates after synchronize rotate (5) by (4):

$$
\left\{\begin{array}{l}
L \frac{d i_{d}}{d t}+R i_{d}-\omega \mathrm{Li}_{\mathrm{q}}=u_{d}-e_{d} \\
L \frac{d i_{\mathrm{q}}}{d t}+R i_{q}+\omega \mathrm{Li}_{\mathrm{d}}=u_{q}-e_{q}
\end{array}\right.
$$

Transform (6):

$$
\left\{\begin{array}{l}
u_{d}=L \frac{d i_{d}}{d t}+R i_{d}-\omega \mathrm{Li}_{\mathrm{q}}+e_{d} \\
u_{q}=L \frac{d i_{q}}{d t}+R i_{q}+\omega \mathrm{Li}_{\mathrm{d}}+e_{q}
\end{array}\right.
$$

\section{FEED-FORWARD DECOUPLING CONTROL}

Just as shown, id and iq are of mutual coupling from (7), which means that if we control one of them, then the other one will be changed correspondingly, thus we can not control them independently. So we need to carry on the decoupling control in order to control them independently.

We use the strategy of feed-forward decoupling control, make

$$
\left\{\begin{array}{l}
L \frac{d i_{d}}{d t}+R i_{d}=\left(\mathrm{K}_{\mathrm{p}}+\frac{\mathrm{K}_{I}}{\mathrm{~s}}\right) *\left(i_{\mathrm{d}}^{*}-i_{\mathrm{d}}\right) \\
L \frac{d i_{q}}{d t}+R i_{q}=\left(\mathrm{K}_{\mathrm{p}}+\frac{\mathrm{K}_{I}}{\mathrm{~s}}\right) *\left(i_{\mathrm{q}}^{*}-i_{\mathrm{q}}\right)
\end{array}\right.
$$

Substitute (8) into (7):

$$
\left\{\begin{array}{l}
u_{d}=\left(\mathrm{K}_{\mathrm{p}}+\frac{\mathrm{K}_{I}}{\mathrm{~s}}\right) *\left(i_{\mathrm{d}}^{*}-i_{\mathrm{d}}\right)-\omega \mathrm{Li}_{\mathrm{q}}+e_{d} \\
u_{q}=\left(\mathrm{K}_{\mathrm{p}}+\frac{\mathrm{K}_{I}}{\mathrm{~s}}\right) *\left(i_{\mathrm{q}}^{*}-i_{\mathrm{q}}\right)+\omega \mathrm{Li}_{\mathrm{d}}+e_{q}
\end{array}\right.
$$

Substitute (9) into (6):

$$
\left\{\begin{array}{l}
\frac{d i_{d}}{d t}=\frac{1}{L}\left(\mathrm{~K}_{p}+\frac{K_{i}}{s}\right) * i_{d}^{*}-\frac{1}{L}\left[\mathrm{R}+\left(\mathrm{K}_{p}+\frac{K_{i}}{s}\right)\right] * \mathrm{i}_{d} \\
\frac{d i_{q}}{d t}=\frac{1}{L}\left(\mathrm{~K}_{p}+\frac{K_{i}}{s}\right) * i_{q}^{*}-\frac{1}{L}\left[\mathrm{R}+\left(\mathrm{K}_{p}+\frac{K_{i}}{s}\right)\right] * \mathrm{i}_{q}
\end{array}\right.
$$

So we can control id and iq independently after decoupling control in (10), thus we can respectively control the active power and reactive power independently and this can make the design of current loop much easier. Current loop design block diagram is shown in Figure 2.

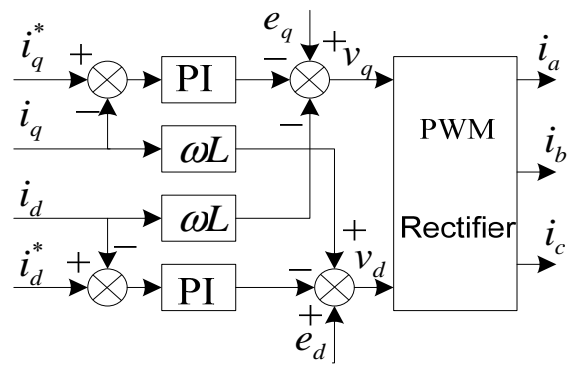

Figure 2. Decoupling control block diagram

For the voltage loop design, the reactive component should be 0 to ensure the PWM rectifier power factor is $1[3,4,5]$. The given value of active component id is produced by PI controller, Which is shown in Eq.(11), the $\mathrm{K}_{\mathrm{uP}}$ is the proportionality factor, the $\mathrm{K}_{\mathrm{uI}}$ is the integral coefficient.

$$
i_{d}^{*}=\left(K_{u P}+\frac{K_{u I}}{s}\right)\left(U_{d c}^{*}-U_{d c}\right)
$$

After double closed loop controlling and coordinate transforming, we can get the control signal under $\alpha-\beta$ twophase stationary coordinate system, such as, $\mathrm{V}_{\alpha}$ and $\mathrm{V}_{\beta}$. Then we can get the rectifier bridge drive signal through SVPWM module. The details of the structure of the SVPWM module are shown in the literature [6]. The system control diagram is shown in Figure 3.

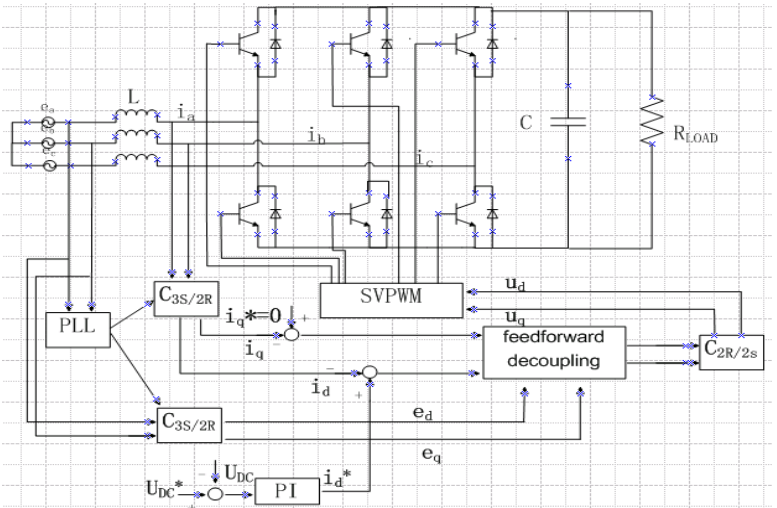

Figure 3. The system control diagram 


\section{Simulation}

There are many reasons, which can affect the eye movement patterns, such as, the size of the amount of the information, the layout of the information and mental overload. Our sight always focused on the main features of the pictures. The eye scan line always turn form one characteristic to another feature of the picture. The identification of the complex picture can be achieved through different levels of information processing. For familiar picture, we will treat it as a unit to identify rather than pay more attention to the details as we already know its main features.

We build the three-phase PWM rectifier and carry on the double closed loop direct current control in the MATLAB / SIMULINK environment after analysis. The control model is shown in Figure 4. The simulation parameters are as follows: the peak value of the power grid voltage phase voltage is $20 \mathrm{~V}$, DC side capacitor is $2200 \mu \mathrm{F}$, the switch frequency is $10 \mathrm{KHz}$, the inductance is $4 \mathrm{mH}$, DC side capacitor voltage is $60 \mathrm{~V}$, the current regulator $\mathrm{K}_{\mathrm{iI}}=10, \mathrm{~K}_{\mathrm{iP}}=$ 5 , the voltage regulator $\mathrm{K}_{\mathrm{uI}}=1, \mathrm{~K}_{\mathrm{uP}}=3.3$.

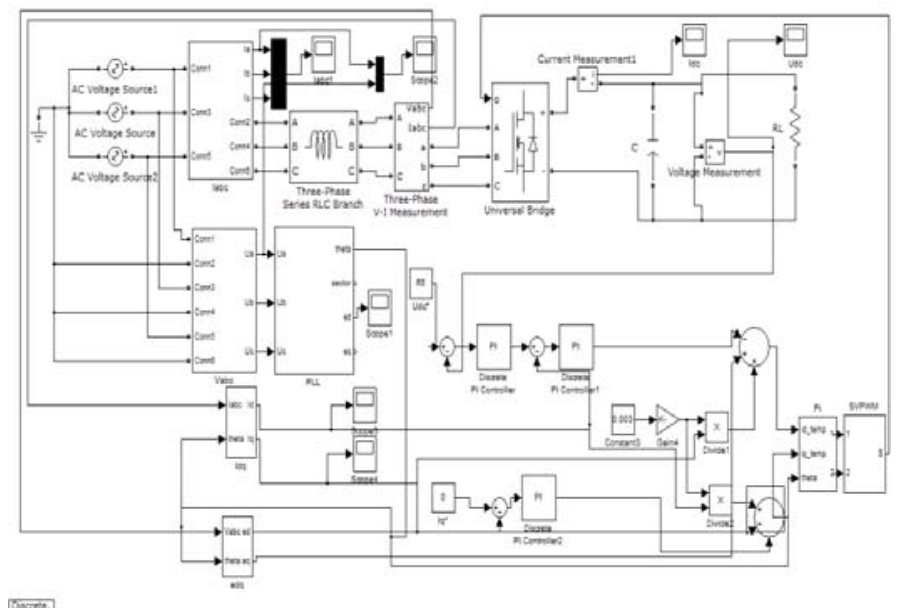

Figure 4. The simulation model

The results of the simulation are shown in Figure 5 and Figure 6 . We can see the DC voltage can be the target value in 0.2 seconds in Figure 5(a). The waveform of the AC side a phase voltage current is shown in Figure 5(b), the current and the voltage own the same phase, and the controlled power factor is approximately 1 . Figure $5(\mathrm{c})$ is the waveform of current in the load mutation experience, and the current tracks the voltage quickly when the load changes to two times, which is originally 0.25 seconds. Figure 5(d) and Figure $5(\mathrm{e})$ is the waveform of reactive and active current respectively, we can see the active and reactive current can be controlled independently, the reactive current is 0 ,verify the system power factor is 1 further. From Figure 6, we can see that the total distortion THD rate of the current harmonic is $4.23 \%$,the switch frequency and its multiple next to the harmonic content are less than the fundamental content'
$2 \%$,so the network side current is sine wave, reduce the harmonic pollution to the power network.

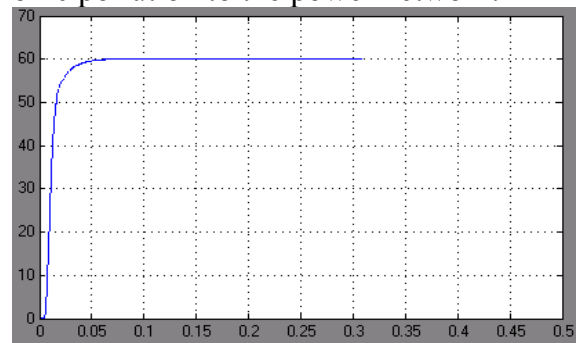

(a) The waveform of DC side voltage

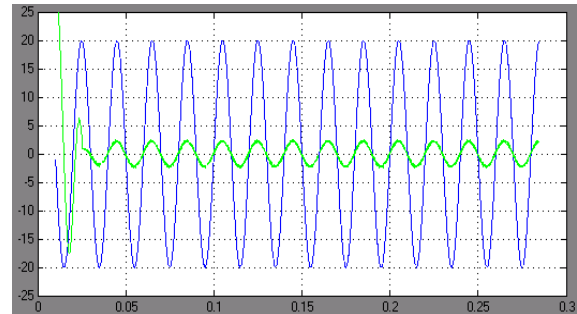

(b) The waveform of AC side a phase voltage current

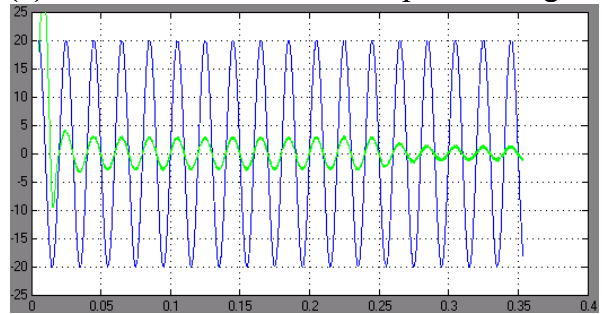

(c) The waveform of current in load mutation experience

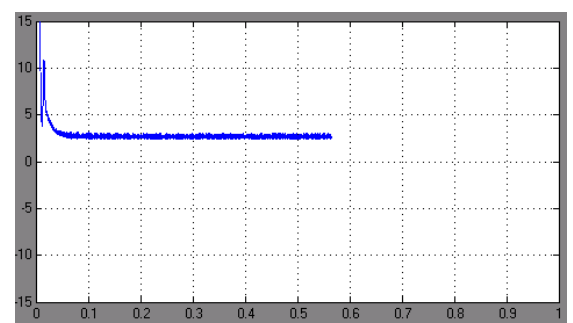

(d) The waveform of active current

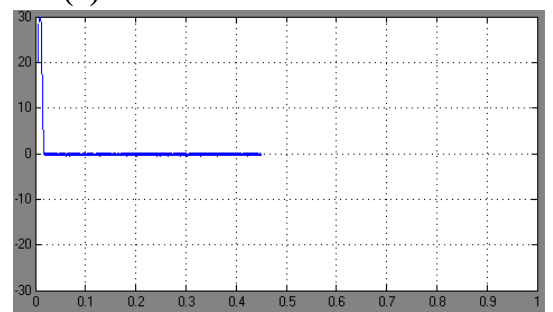

(e) The waveform of reactive current

Figure 5. The results of the simulation:(a) The waveform of DC side voltage.(b) The waveform of AC side a phase voltage current.(c) The waveform of current in load mutation experience.(d) The waveform of active current.(e) The waveform of reactive current. 


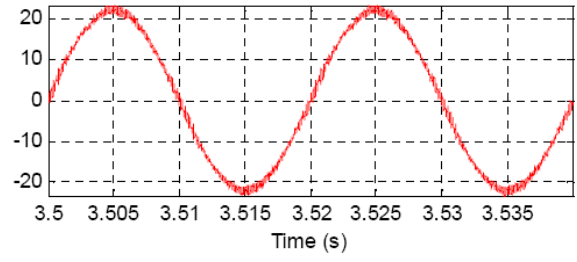

FFT analysis

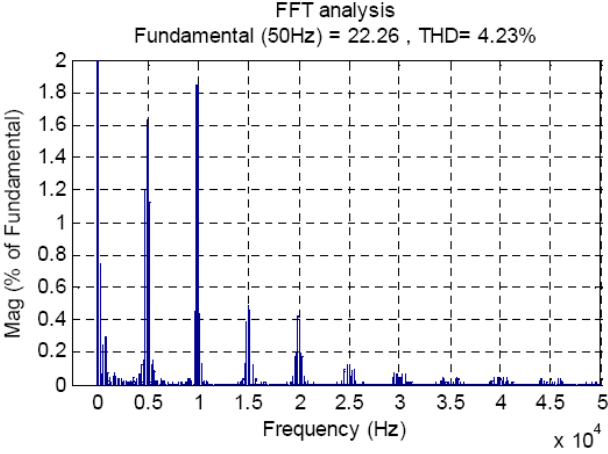

Figure 6. The waveform of harmonic

\section{RESULTS}

The PWM rectifier control system is designed and realized in the paper. In the system, The main control chip is TI company' DSP2812, AC input voltage is $12 \mathrm{~V}$, AC side inductance is $4 \mathrm{mH}$, DC side support capacitance is $2500 \mu \mathrm{F}$, DC voltage is $30 \mathrm{~V}$, DC side load is $20 \Omega$ power resistance.

Figure 7 is the results of the experience. Figure 7 (a) is the waveform of a phase voltage and current,Figure 7(b) is the waveform of DC side voltage. We can see the voltage and the current own the same phase from Figure 7 (a), and the power factor is 1 . The value of the DC side output voltage is the given one form Figure 7 (b).

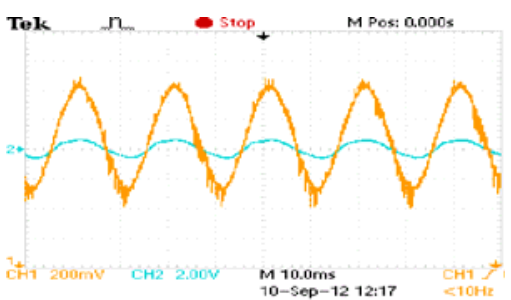

(a) The waveform of a phase voltage and current

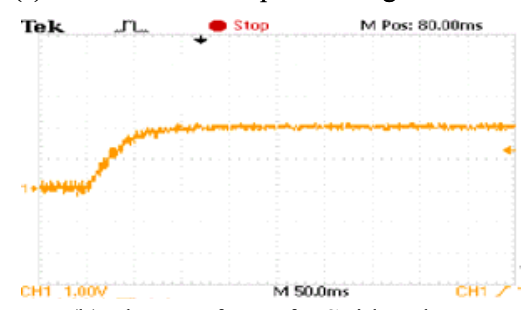

(b) The waveform of DC side voltage

Figure 7. The result of the experiment: (a) The waveform of a phase voltage and current. (b) The waveform of DC side voltage.

\section{CONCLUSION}

In the paper, the mathematical model of three-phase voltage-source PWM rectifier, is analyzed .Then based on the idea of the feed-forward decoupling control, the method of the voltage current double closed loop control is adapted. We built the system of PWM rectifier finally after simulating in the MATLAB /SIMULINK environment. The simulating and test results have shown that the system based on feedforward decoupling control has high dynamic performance and steady-state.

\section{REFERENCES}

[1] J. Liao, S, Yeh, "A novel Instantaneous Power Control Strategy and Analytic Model for Integrated Rectifier/inverter Systems,'IEEE Trans. on Power Electronics,vol. 15,2000, pp. 996-1006.

[2] B.R. Lin, "Analysis and Implementation of a Three-level PWM Rectifier/Inverter,'IEEE Trans. on Aerospace and Electronic Systems,vol. 3,2000,pp. 948-956.

[3] B.R. Lin, H.H. Lu, Y.L. Huo, "Single-phase Power Factor Correction Circuit with Three-Level Boost Converter, ”IEEE,2000,pp. 278-283.

[4] P. C. Loh, M. J. Newman, D. N. Zmood, and D. G. Holmes, "Improved transient and steady state voltage regulation for single and three phase uninterruptible power supplies," in Proc. 32nd Ann. IEEE Power Electron.Spec. Conf,2001,(PESC'01).

[5] D. Zmood, D. Holmes, and G. Bode, "Frequency-domain analysis of three-phase linear current regulators," IEEE Trans. Ind. Application, vol. 37, 2001,pp. 601-610.

[6] S.H. Cheng, "The SVPWM simulation in simulink." vol.31. Electrical Automation,vol. 24,2002,pp.38-41 